JIKSH: Jurnal Ilmiah Kesehatan Sandi Husada
https://akper-sandikarsa.e-journal.id/JIKSH
Volume 10| Nomor 1| Juni|2021
e-ISSN: 2654-4563 dan p-ISSN: 2354-6093
DOI: https:/doi.org/10.35816/jiskh.v10i1.606

\title{
Researh Articel \\ Sikap Asertif Perawat dalam Memberikan Pelayanan Keperawatan di Instalasi Rawat Inap di Rumah Sakit
}

\author{
Rahmat Pannyiwi ${ }^{1}$, Nurhaedah Nurhaedah ${ }^{2}$, Andi Hariati ${ }^{3}$ \\ 1,2 Departmen Keperawatan, STIKES Amanah
}

\begin{tabular}{|c|c|}
\hline Article Info & Abstrak \\
\hline $\begin{array}{l}\text { Article History: } \\
\text { Received:28-03-2021 } \\
\text { Reviewed: 20-04-2021 } \\
\text { Revised: 06-05-2021 } \\
\text { Accepted: 22-05-2021 } \\
\text { Published: 30-06-2021 } \\
\text { Key words; } \\
\text { Persepsi pasien; } \\
\text { Carring; } \\
\text { Perawat; }\end{array}$ & $\begin{array}{l}\text { Pendahuluan; Era globalisasi yang sedang dan akan kita hadapi } \\
\text { dibidang kesehatan menimbulkan secercah harapan akan } \\
\text { peluang meningkatnya pelayanan kesehatan. Tujuan; } \\
\text { mengetahui sikap asertif perawat dalam memberikan pelayanan } \\
\text { keperawatan di instalasi rawat inap di rumah Sakit. Metode; } \\
\text { penelitian deskriptif menggambarkan tentang tingkat } \\
\text { pendidikan, pengalaman kerja, dan jenis kelamin terhadap sikap } \\
\text { asertif perawat. Hasil; menunjukkan bahwa komunikasi verbal } \\
38 \text { (69,1 \%), komunikasi non verbal } 39 \text { ( } 70,9 \% \text { ) dan faktor yang } \\
\text { mempengaruhi komunikasi verbal dan non verbal } 30 \text { (54,5\%). } \\
\text { Kesimpulan; bahwa dalam memberikan pelayanan keperawatan, } \\
\text { perawat dapat menunjukkan perilaku yang tidak asertif karena } \\
\text { dipengaruhi oleh beberapa faktor, contoh faktor lingkungan. } \\
\text { Lingkungan interaksi akan mempengaruhi komunikasi yang } \\
\text { efektif. } \\
\text { Abstract. Introduction; The era of globalization that is being } \\
\text { and will be faced by us in the health sector raises a glimmer of } \\
\text { hope for the opportunity to improve health services. Objectives; } \\
\text { know the assertiveness of nurses in providing nursing services } \\
\text { in inpatient installations at hospitals. Method; Descriptive } \\
\text { research describes the level of education, work experience, and } \\
\text { gender towards the assertiveness of nurses. Result; shows that } \\
\text { verbal communication } 38 \text { ( } 69.1 \% \text { ), non verbal communication } \\
39 \text { ( } 70.9 \% \text { ) and the factors that influence verbal and non-verbal } \\
\text { communication } 30 \text { ( } 54.5 \% \text { ). Conclusion; that in providing } \\
\text { nursing services, nurses can show non-assertive behavior } \\
\text { because it is influenced by several factors, for example } \\
\text { environmental factors. The interaction environment will affect } \\
\text { effective communication. }\end{array}$ \\
\hline $\begin{array}{l}\text { Corresponding author } \\
\text { Email }\end{array}$ & $\begin{array}{l}\text { hmat Pannyiwi } \\
\text { amatpannyiwi79@gmail.com }\end{array}$ \\
\hline
\end{tabular}

\section{Pendahuluan}

Rumah sakit merupakan perusahaan pelayanan jasa, dimana produk yang dihasilkan sifatnya tidak berwujud (intangible) dan berasal dari pemberi pelayanan tersebut yang dalam hal ini adalah petugas atau kita sebut SDM. Pembangunan kesehatan merupakan salah satu cara untuk meningkatkan kesadaran, kemauan dan kemampuan hidup sehat bagi setiap orang sehingga tercapai derajat kesehatan masyarakat yang optimal (Suprapto et al., 2021). Perawat juga memiliki tempat yang penting dalam presentasi layanan kesehatan, secara alami perawat 
JIKSH: Jurnal Ilmiah Kesehatan Sandi Husada

Volume 10 Nomor 1 Juni 2021

mengembangkan model seperti sikap terhadap organisasi rumah sakit dan profesi keperawatan. Sikap terhadap pekerjaan dan lingkungan (S. Suprapto, 2021).

Menurut (Pananrangi. M et al., 2020) bahwa semakin meningkatnya kesadaran masyarakat akan haknya dalam memeperoleh pelayanan termasuk pelayanan kesehatan merupakan salah satu indikator positif meningkatnya kesadaran akan pentingnya kesehatan Tuntutan masyarakat akan mutu pelayanan kesehatan terutama pelayanan keperawatan saat ini tidak bisa dielakan lagi. Hal ini terjadi karena masyarakat telah menyadari akan arti kesehatan dan kompleksitas masalah kesehatan. Tenaga perawat merupakan tenaga yang paling banyak kontak dan berinteraksi dengan pasien, sehingga pasien cenderung menilai dan mengamati apa yang mereka lakukan. Disiplin merupakan tolak ukur untuk mengetahui apakah peran seorang manajer atau pemimpin secara keseluruhan dapat dilaksanakan dengan baik atau tidak (T. C. M. Suprapto \& Lalla, 2020). Aspek yang sering dinilai pasien adalah perilaku perawat dalam merawat. Perilaku yang diharapkan adalah perilaku asertif yaitu perilaku bagaimana seseorang mengekspresikan pikiran atau perasaan seseorang dengan cara berkomunikasi dengan jujur dan tidak menyinggung perasaan orang lain. Mutu pelayanan kesehatan adalah yang menunjuk pada tingkat kesempurnaan pelayanan kesehatan dalam menimbulkan rasa puas pada diri setiap pasien. Makin sempurna kepuasan yang dirasakan, makin baik pula kualitas pelayanan kesehatan (Pannyiwi, 2016). Tujuan: mengetahui sikap asertif perawat dalam memberikan pelayanan keperawatan di instalasi rawat inap di Rumah sakit.

\section{Metode}

Jenis penelitian deskriptif, penelitian dilaksanakan di ruang rawat inap. Populasi semua perawat yang ada di Instalasi Rawat Inap 121 orang. Sampel yang diteliti di Instalasi Rawat Inap sebanyak 55 orang. Teknik pengambilan sampel dengan menggunakan teknik non probability sampling dengan teknik consecutive sampling yang memenuhi kriteria inklusi. Pengumpulan data dilakukan dengan kuesioner yang dibagikan. Analisa yang digunakan analisa univariat yang menghasilkan distribusi dan frekuensi dari tiap variabel yang diteliti. Pengolahan data dilakukan dengan menggunakan bantuan Program SPSS 21.

\section{Hasil Dan Pembahasan}

Tabel 1

Karakteristik Responden Berdasarkan Umur di Instalasi Rawat Inap

\begin{tabular}{lcc}
\hline Umur (Tahun) & Frekuensi & Persentase $(\%)$ \\
\hline $18-40$ & 45 & 81,8 \\
$41-60$ & 10 & 18,2 \\
\hline Total & 55 & 100 \\
\hline Jenis Kelamin & & \\
\hline Laki-laki & 8 & 14,5 \\
Perempuan & 47 & 85,5 \\
\hline Total & 55 & 100 \\
\hline Pendidikan & & 74,5 \\
\hline D3 & 41 & 25,5 \\
S1 & 14 & 100 \\
\hline Total & 55 & 72,7 \\
Pengalaman Kerja & & 27,3 \\
\hline$<11$ tahun & 40 & 100 \\
\hline 11 tahun & 15 &
\end{tabular}

Sumber : Data Primer 
Rahmat Pannyiwi, dkk. Sikap Asertif Perawat dalam Memberikan Pelayanan........

Tabel 2

Komunikasi Verbal Perawat di Instalasi Rawat Inap

\begin{tabular}{lcc}
\hline \multicolumn{1}{c}{ Komunikasi Verbal } & Frekuensi & Persentase $\mathbf{( \% )}$ \\
\hline Baik & 38 & 69,1 \\
Kurang & 17 & 30,9 \\
\hline Total & $\mathbf{5 5}$ & $\mathbf{1 0 0}$ \\
\hline Komunikasi Non Verbal & & 70,9 \\
\hline Baik & 39 & 29,1 \\
Kurang & 16 & $\mathbf{1 0 0}$ \\
\hline Total & $\mathbf{5 5}$ & \\
\hline Faktor-Faktor yang Mempengaruhi Komunikasi Verbal dan Non \\
Verbal & & 54,5 \\
\hline Baik & 30 & 45,5 \\
Kurang & 25 & $\mathbf{1 0 0}$ \\
\hline Total & $\mathbf{5 5}$ &
\end{tabular}

\section{Pembahasan}

Sumber : Data Primer 2014

Komunikasi Verbal, berdasarkan hasil penelitian menunjukkan bahwa dari 55 responden, responden dengan komunikasi verbal yang baik sebanyak 38 orang atau $(69,1 \%)$, sedangkan responden dengan komunikasi verbal yang kurang sebanyak 17 orang atau $(30,9 \%)$. Komunikasi verbal adalah komunikasi yang menggunakan kata-kata, entah lisan maupun tulisan. Komunikasi ini paling banyak dipakai dalam hubungan antar manusia. Melalui katakata, mereka mengungkapkan perasaan, emosi, pemikiran, gagasan, atau maksud mereka, menyampaikan fakta, data, dan informasi serta menjelaskannya, saling bertukar perasaan dan pemikiran, saling berdebat, dan bertengkar.

Hasil penelitian (Syagitta et al., 2017) bahwa persepsi perawat terhadap pelaksanaan komunikasi efektif. Tema pertama adalah pelaksanaan komunikasi efektif di instalasi rawat jalan berjalan baik, masih adanya hambatan yang dirasakan perawat ketika melakukan komunikasi efektif, dan pola komunikasi perawat-klien mempengaruhi tingkat kepuasan klien terhadap pelayanan. Saran dari penelitian ini adalah diharapkan agar perawat lebih meningkatkan keterampilan komunikasi efektifdalam rangka meningkatkan kualitas pelayanan. Menurut (Arda, 2019) bahwa komunikasi adalah bagian penting dari kehidupan manusia. Kemampuan perawat dalam melakukan komunikasi terapeutik merupakan hal yang penting dalam pelaksanaan asuhan keperawatan. Bahwa (S. Suprapto et al., 2020) bahwa terdapat hubungan antara sikap, keterampilan dan pengetahuan dalam pelaksanaan kesehatan.

Komunikasi Non Verbal, berdasarkan hasil penelitian menunjukkan bahwa dari 55 responden, responden dengan komunikasi non verbal yang baik sebanyak 39 orang atau $(70,9 \%)$, sedangkan responden dengan komunikasi non verbal yang kurang sebanyak 16 orang atau $(29,1 \%)$. Komunikasi non-verbal adalah pemindahan pesan tanpa menggunakan katakata. Merupakan cara yang paling meyakinkan untuk menyampaikan pesan kepada orang lain. Perawat perlu menyadari pesan verbal dan non-verbal yang disampaikan klien mulai dari saat pengkajian sampai evaluasi asuhan keperawatan, karena isyarat non-verbal menambah arti terhadap pesan verbal. Perawat yang mendektesi suatu kondisi dan menentukan kebutuhan asuhan keperawatan. Dari hasil penelitian dapat dilihat bahwa sebagian besar perawat yang bertugas di Instalasi Rawat telah melaksanakan komunikasi non verbal dengan baik.

Komunikasi non verbal adalah komunikasi yang mencakup seluruh indera dan semua hal yang tidak melibatkan kata tertulis (Potter \& Perry, 2010) Sikap tubuh dan langkah menggambarkan sikap; emosi, konsep diri dan keadaan fisik. Perawat harus menyadari emosinya ketika sedang berinteraksi dengan klien, karena maksud untuk menyamakan rasa tertarik yang tulus terhadap klien dapat terhalangi oleh nada suara perawat. Perawat memegang 
JIKSH: Jurnal Ilmiah Kesehatan Sandi Husada

Volume 10 Nomor 1 Juni 2021

peranan penting dalam meningkatkan kualitas pelayanan demi kepuasan pasien (Suprapto Suprapto, 2018). Jarak yang digunakan ketika berkomunikasi dengan orang lain, termasuk juga tempat atau lokasi posisi perawat berada. Pengaturan jarak menentukan seberapa jauh atau seberapa dekat tingkat keakraban perawat dengan orang lain, menunjukkan seberapa besar penghargaan, suka atau tidak suka dan perhatian perawat terhadap orang lain, selain itu juga menunjukkan simbol sosial. Hasil penelitian (Justisiani, 2014) bahwa persepsi masyarakat tentang bentuk komunikasi verbal dan komunikasi nonverbal dalam memberikan pelayanan kepada pengunjung atau pasien di Rumah Sakit.

Faktor yang Mempengaruhi Komunikasi Verbal dan Non Verbal, berdasarkan hasil penelitian menunjukkan bahwa dari 55 responden, responden dengan faktor-faktor yang mempengaruhi komunikasi verbal dan non verbal yang baik sebanyak 30 orang atau $(54,5 \%)$, sedangkan responden dengan faktor-faktor yang mempengaruhi komunikasi verbal dan non verbal yang kurang sebanyak 25 orang atau $(45,5 \%)$.

Menurut (Potter \& Perry, 2010) bahwa proses komunikasi dipengaruhi oleh beberapa faktor, yaitu: perkembangan, persepsi, nilai, latar belakang sosial budaya, emosi, jenis kelamin, pengetahuan, peran dan hubungan, lingkungan serta jarak.Agar dapat berkomunikasi efektif dengan pasien, perawat harus mengerti pengaruh dari perkembangan usia baik dari sisi bahasa maupun proses fikir dari pasien tersebut. Karena tiap tahap perkembangan atau umur klien yang berbeda mempunyai tingkat kemampuan memahami maksud dari isi komunikasi yang perawat sampaikan (Kurniati, 2016). Persepsi adalah pandangan pribadi seseorang terhadap suatu kejadian atau peristiwa, dan dibentuk oleh harapan atau pengalaman. Perbedaan persepsi antara perawat-pasien dapat mengakibatkan terhambatnya komunikasi. Komunikasi verbal adalah komunikasi dengan menggunakan simbol vebal. Simbol verbal bahasa merupakan suatu impresi pencapaian manusia. Ada aturan untuk setiap bahasa yaitu fonologi, sintaksis, semanctc, dan pragmatis. Sedangkan komunikasi nonverbal adalah proses komunikasi dimana pesan yang dikirimkan tidak menggunakan kata-kata (Kusumawati, 2019).

Nilai adalah standar yang mempengaruhi perilaku, sehingga penting bagi perawat untuk menyadari nilai seseorang. Perawat perlu berusaha untuk mengetahui dan mengklarifikasi nilai sehingga dapat membuat keputusan dan interaksi yang tepat dengan klien. Bahasa dan gaya komunikasi akan sangat dipengaruhi oleh faktor budaya, dan budaya ini juga yang membatasi cara bertindak dan berkomunikasi. Klien sebagai manusia pasti mempunyai budaya yang berbeda-beda antara yang satu dan yang lain. Emosi merupakan perasaan subjektif terhadap suatu kejadian. Ekspresi emosi seperti sedih, senang, dan terharu dapat mempengaruhi orang lain dalam berkomunikasi. Perawat perlu mengkaji emosi klien dan keluarganya sehinnga perawat dapat memberikan asuhan keperawataan yang tepat (Elzawan \& Yuningsih, 2016).

Menurut (Saputra \& Imalah, 2017) bahwa ada hubungan yang signifikan antara keterampilan komunikasi verbal dan non verbal dengan kesiapan kerja menjadi perawat. Pasien yang tingkat pengetahuannya rendah akan sulit berespon dengan pertanyaan mengandung bahasa verbal dibanding dengan orang yang tingkat pengetahuannya tinggi. Jadi perawat perlu untuk mengetahui tingkat pengetahuan klien agar bisa berinteraksi dengan baik. Gaya komunikasi sesuai dengan peran dan hubungan diantara orang yang berkomunikasi. Seorang perawat berkomunikasi dengan teman sejawatnya pasti akan berbeda ketika berkomunikasi kepada kliennya. Jadi seorang perawat harus bisa menggunakan gaya bahasa yang berbeda-beda pada lawan bicaranya berdasarkan peran dan hubungan, terutama dengan klien (S. Suprapto, 2020).

\section{Kesimpulan Dan Saran}

Bahwa sebagian besar perawat yang bertugas di Instalasi Rawat telah melaksanakan komunikasi non verbal dengan baik. Seorang perawat harus bisa berkomunikasi dengan baik, 
Rahmat Pannyiwi, dkk. Sikap Asertif Perawat dalam Memberikan Pelayanan........

berkomunikasi dengan sesama perawat maupun dengan pasien dengan menggunakan komunikasi verbal dan non-verbal dengan baik.

\section{Ucapan Terima Kasih}

Penulis menyampaikan ucapan terima kasih dan penghargaan kepada direktur RS. Islam Faisal Makassar beserta jajaannya, yang telah memberikan kesempatan dalam melakukan kegiatan akademik dan seluruh.

\section{Daftar Rujukan}

Arda, D. (2019). Pengetahuan Perawat Tentang Komunikasi Terapeutik Di Rumah Sakit. Jurnal Ilmiah Kesehatan Sandi Husada, 8(2 SE-Articles). https://doi.org/10.35816/jiskh.v10i2.117

Elzawan, M., \& Yuningsih, A. (2016). Pola Komunikasi Verbal Dan Non Verbal Dalam Seni Benjang. Prosiding Hubungan Masyarakat ISSN, 2460, 6510.

Justisiani, E. I. (2014). Persepsi Masyarakat Tentang Bentuk Komunikasi Verbal Dan Komunikasi Nonverbal Pada Pelayanan Rumah Sakit Umum Daerah Abdul Wahab Sjahranie Samarinda. Jurnal Ilmu Komunikasi, 2(3), 193-206.

Kurniati, D. P. Y. (2016). Modul Komunikasi Verbal dan Non Verbal. Universitas Udayana: Fakultas Kedokteran.

Kusumawati, T. I. (2019). Komunikasi verbal dan nonverbal. AL-IRSYAD, 6(2).

Pananrangi.M, A., Nippi, A., Panyyiwi, R., \& Suprapto, S. (2020). Quality of Health Services at Public Health Center Padongko. Jurnal Ilmiah Kesehatan Sandi Husada, 12(2 SE-Articles). https://doi.org/10.35816/jiskh.v12i2.398

Pannyiwi, R. (2016). Study Mutu Pelayanan Kesehatan Pada Pasien Rawat Inap Di Rumah Sakit Umum Daerah Arifin Nu'mang Kab. Sidenreng Rappang. Sosial Kesehatan LPPM STIKes Mega Rezky Makassar, 2(1), 125-140.

Potter, P. A., \& Perry, A. G. (2010). Fundamental Keperawatan, Buku 3.

Saputra, D. C., \& Imalah, R. N. (2017). Hubungan Keterampilan Komunikasi Verbal Dan Non Verbal Dengan Kesiapan Kerja Menjadi Ners Pada Mahasiswa Ilmu Keperawatan Universitas 'Aisyiyah Yogyakarta.

Suprapto, Mulat, T. C., \& Lalla, N. S. N. (2021). Nurse competence in implementing public health care. International Journal of Public Health Science, 10(2), 428-432. https://doi.org/10.11591/ijphs.v10i2.20711

Suprapto, S. (2020). Penerapan Asuhan Keperawatan Pada Gangguan Sistem Pencernaan "Gastritis." Jurnal Ilmiah Kesehatan Sandi Husada, 11(1 SE-Articles). https://doi.org/10.35816/jiskh.v11i1.211

Suprapto, S. (2021). Capacity Building For Nurses In Health Services In Hospitals. IN Patent $000,235,157$.

Suprapto, S., Herman, H., \& Asmi, A. (2020). Nurse Competency and Managing Level of Community Health Care Activities. Jurnal Ilmiah Kesehatan Sandi Husada, 12(2 SEArticles). https://doi.org/10.35816/jiskh.v12i2.386

Suprapto Suprapto. (2018). Hubungan Komitmen Dan Kepuasan Perawat Dengan Prestasi Kerja Perawat Pelaksana Rumah Sakit DiMakassar. JIKSH: Jurnal Ilmiah Kesehatan Sandi Husada, 7(2 SE-Articles). https://doi.org/10.35816/jiskh.v8i2.59

Suprapto, T. C. M., \& Lalla, N. S. N. (2020). Environmental and Personality Influences on Nurse Discipline Public Health Center. International Journal of Nursing Education, 12(4), 271-274. https://doi.org/https://doi.org/10.37506/ijone.v12i4.11262

Syagitta, M., Sriati, A., \& Fitria, N. (2017). Persepsi Perawat Terhadap Pelaksanaan Komunikasi Efektif di IRJ Al-Islam Bandung. Jurnal Keperawatan BSI, 5(2). 